\title{
Factors controlling Arctic denitrification in cold winters of the 1990s
}

\author{
G. W. Mann, S. Davies, K. S. Carslaw, and M. P. Chipperfield \\ Institute for Atmospheric Science, School of the Environment, University of Leeds, Leeds, UK \\ Received: 2 November 2002 - Published in Atmos. Chem. Phys. Discuss.: 18 December 2002 \\ Revised: 3 March 2003 - Accepted: 24 March 2003 - Published: 3 April 2003
}

\begin{abstract}
Denitrification of the Arctic winter stratosphere has been calculated using a 3-D microphysical model for the winters 1994/95, 1995/96, 1996/97 and 1999/2000. Denitrification is assumed to occur through the sedimentation of low number concentrations of large nitric acid trihydrate (NAT) particles (as inferred by e.g. Fahey et al., 2001). We examine whether the meteorological conditions that allowed particles to grow to the very large sizes observed in 1999/2000 also occurred in the other cold winters. The results show that winter 1999/2000 had conditions that were optimum for denitrification by large NAT particles, which are a deep concentric NAT area and vortex. Under these conditions, NAT particles can circulate in the NAT-supersaturated air for several days, reaching several micrometres in radius and leading to a high downward flux of nitric acid. The other winters had shorter periods with optimum conditions for denitrification. However, we find that NAT particles could have grown to large sizes in all of these winters and could have caused significant denitrification. We define the quantity "closedflow area" (the fraction of the NAT area in which air parcel trajectories can form closed loops) and show that it is a very useful indicator of possible denitrification. We find that even with a constant NAT nucleation rate throughout the NAT area, the average NAT number concentration and size can vary by up to a factor of 10 in response to this meteorological quantity. These changes in particle properties account for a high degree of variability in denitrification between the different winters. This large meteorologically induced variability in denitrification rate needs to be compared with that which could arise from a variable nucleation rate of NAT particles, which remains an uncertain quantity in models. Sensitivity studies show that although denitrification was likely approaching asymptotic minimum values throughout much of the 1999/2000 vortex, decreases in the volume-averaged nucleation rate would have substantially reduced the denitrification.
\end{abstract}

Correspondence to: G. Mann (gmann@env.leeds.ac.uk)

\section{Introduction}

Extensive denitrification was observed in $1999 / 2000$ by both in situ (Popp et al., 2001) and remote (Santee et al., 2000; Kleinböhl et al., 2002) instruments. Large nitric acidcontaining particles (10 to $20 \mu \mathrm{m}$ diameter) at low number concentrations (between $10^{-5}$ and $10^{-3} \mathrm{~cm}^{-3}$ ) were measured by the NOAA NO $\mathrm{N}_{y}$ instrument aboard the NASA ER-2 aircraft in the 1999/2000 winter Arctic vortex and have generally been inferred to be NAT (Fahey et al., 2001; Northway et al., 2002a). Previous model calculations (Carslaw et al., 2002; Drdla et al., 2002) show that meteorological conditions in the 1999/2000 Arctic vortex allowed NAT particles to grow to the very large sizes that were observed. These large particles can very efficiently denitrify the lower stratosphere on the timescale of a few days (Fahey et al., 2001; Mann et al., 2002; Northway et al., 2002b; Davies et al., 2002).

The large-particle observations in the 1999/2000 Arctic vortex constitute the first unambiguous detection of large, sedimenting nitric acid-containing particles. These observations, and model simulations of their development, prompt several questions:

1. Could NAT particles have grown to such very large sizes in other winters, or did the 1999/2000 Arctic vortex have unique properties to allow their development? There are no observations from previous Arctic winters to directly answer this question. For example, the Aerosol Particle Counter of Deshler and Oltmans (1998) has a lower detection limit of $6 \times 10^{-4} \mathrm{~cm}^{-3}$, so would not have been able to detect many of the populations of large particles in 1999/2000. The Forward Scattering Spectrometer Probe (FSSP) instrument detected $13 \mu \mathrm{m}$ diameter particles in the Arctic stratosphere during January 1989 (Dye et al., 1992) but these cannot be attributed unambiguously to nitric acid particles.

2. How much denitrification could have been caused in 1999/2000 and in other winters by such particle popula-

(C) European Geosciences Union 2003 
tions? There are observations of denitrification in each of the cold winters 1994/5 (Sugita et al., 1998; Waibel et al., 1999), 1995/6 (Hintsa et al., 1998; Dessler et al, 1999), 1996/7 (Kondo et al., 2000; Irie et al., 2001) and 1999/2000 (Santee et al., 2000; Popp et al., 2001; Kleinböhl et al., 2002). See also Santee et al. (1999) for MLS measurements of denitrification between 1991 and 1998. Here, we do not compare model simulations with these observations in detail, but establish the potential for denitrification by NAT particles.

3. Thirdly, what are the factors that control denitrification by low number densities of NAT particles? Vortex-scale modelling of denitrification by Mann et al. (2002) has shown that the dynamics of the Arctic vortex can control denitrification by determining the length of time a NAT particle stays below the NAT equilibrium temperature $T_{\text {NAT }}$ (around $195 \mathrm{~K}$ ). It was shown that the optimum situation for denitrification is a large NAT region that is concentric with the polar vortex. However, the simulations illustrating this sensitivity were only 10 days long and examined a specific set of conditions. Here we perform complete winter simulations of denitrification of the Arctic vortex for the four coldest winters of the 1990s: 1994/95, 1995/96, 1996/97 and 1999/2000.

Several factors may influence the magnitude and extent of denitrification, including nitric acid and water mixing ratios, vertical depth of the NAT region, NAT region size, minimum temperature, and hydrate particle number concentrations (e.g. Jensen et al., 2002). Variations in all of these factors, except the latter, are present in the meteorological and trace gas initialisation fields used here. In addition, Mann et al. (2002) have shown that the magnitude of denitrification by low number concentrations of large NAT particles depends critically on the colocation of the NAT region and the vortex. Under conditions where the vortex and NAT region are concentric, individual NAT particles can be advected in NAT-supersaturated air for several days, eventually growing to sizes of several micrometres. In contrast, a highly baroclinic vortex, in which the centre of the NAT region is positioned towards the edge of the vortex, means that individual NAT particles experience short periods of low temperature followed by warming and particle evaporation. Dynamical situations that allow a sedimenting particle to remain below the NAT saturation temperature for $\sim 8$ days will be optimum for denitrification (Fahey et al., 2001; Mann et al., 2002). This sensitivity to vortex concentricity will decrease as the particle number concentration increases due to the shorter time required for the particles to reach their final size when equilibrium with gas phase $\mathrm{HNO}_{3}$ is attained (Jensen et al., 2002). The model predictions we show here assume low number concentrations of NAT particles, as observed in winter 1999/2000, so sensitivity to vortex concentricity can be expected.
In Mann et al. (2002) we defined the concentricity of the NAT area and vortex in terms of the separation of their centroids. In one case study, using a highly idealized approach, we showed that the calculated vortex-average denitrification fell linearly from some maximum value to zero as the NAT area centroid was moved from the centroid of the vortex to the vortex edge. Here, we show that the NAT area-vortex centroid separation is a useful quantity for understanding the magnitude of denitrification in several recent winters.

\section{Description of the model}

The model is described fully in Carslaw et al. (2002) and Mann et al. (2002). Briefly, the model consists of a Lagrangian particle model incorporating the formation, advection, growth and sedimentation of several thousand NAT particles coupled to the 3-D Eulerian off-line stratospheric chemical transport model (CTM) SLIMCAT (e.g. Chipperfield, 1999). This off-line CTM is normally run with a 41 tracer chemistry reaction scheme, but for the purposes of these simulations where the denitrification model must be solved at each time step, a reduced 4 tracer scheme is used which includes $\mathrm{NO}_{y}$, a passive $\mathrm{NO}_{y}$ tracer (with no denitrification), $\mathrm{H}_{2} \mathrm{O}$ and $\mathrm{H}_{2} \mathrm{SO}_{4}$ (used to calculate background aerosol mass). These 4 tracers enable the effect of microphysics on fields of $\mathrm{NO}_{y}$ to be examined with the chemistry switched off. An assumption is made that the model $\mathrm{NO}_{y}$ is equivalent to $\mathrm{HNO}_{3}$, which is reasonable for the lower polar winter stratosphere. The chemical tracers are advected using the second-order moments scheme of Prather (1986), which has low numerical diffusion and performs well in preserving strong gradients. The model is forced by $6-\mathrm{h}$ wind and temperature fields from European Centre for MediumRange Weather Forecasts (ECMWF) operational analyses, while vertical tracer advection is calculated in isentropic coordinates from heating rates using the MIDRAD radiation scheme (Shine, 1987). For all the simulations in this paper, the CTM has T21 horizontal resolution $\left(5^{\circ}\right.$ latitude and longitude) with a $10 \mathrm{~K}$ vertical resolution for the gas phase fields between 350 and $600 \mathrm{~K}$.

The particle model calculates the change in gas phase $\mathrm{HNO}_{3}$ concentrations caused by time-dependent particle growth and evaporation and feeds this back to the CTM part of the model, which then advects the gas phase species. Particle growth is calculated in the microphysical model as in Appendix A taking into account the advected gas phase $\mathrm{HNO}_{3}$ and $\mathrm{H}_{2} \mathrm{O}$. The 3-D particle advection and trace gas advection are done with the same time step of 30 minutes. The Eulerian CTM thus produces daily fields of denitrification calculated as the difference between the total $\mathrm{HNO}_{3}$ and the passive $\mathrm{HNO}_{3}$. The passive $\mathrm{HNO}_{3}$ has the particle sedimentation switched off (and hence no denitrification). The model incorporates the removal of gas phase nitric acid and water by supercooled ternary solution (STS) droplets using the analyt- 
ical scheme of Carslaw et al. (1995). The gas phase $\mathrm{HNO}_{3}$ in equilibrium with STS is used to calculate NAT particle growth, so STS formation in the model has the effect of reducing the rate of NAT particle growth.

The coupled model is initialised each winter in early December with 3-dimensional fields of gas phase nitric acid and water from multiannual SLIMCAT simulations. These compare reasonably well with observations from 1999/2000 and 1996/7 below $700 \mathrm{~K}$.

We use a volume-average NAT nucleation rate of $8.1 \times$ $10^{-10}$ particles $\mathrm{cm}^{-3} \mathrm{~s}^{-1}$, which has been shown to reproduce very well changes in the particle number concentration observed in the period January to March 2000 (Carslaw et al., 2002). Particles are initialised with a diameter of $0.1 \mu \mathrm{m}$. The particle number concentrations produced in the vortex by assuming this nucleation rate (maxima of $\sim 10^{-5}-10^{-4}$ $\mathrm{cm}^{-3}$ ) are at the low end of concentrations that can cause denitrification (Jensen et al., 2002). The sensitivity of denitrification to this chosen nucleation rate is explored for one of the winters.

We use this same nucleation rate in all the winter-long simulations for two reasons. Firstly, a constant nucleation rate allows us to evaluate the importance of meteorological factors in controlling NAT particle evolution and sedimentation in isolation. Secondly, our current understanding of the origin of large NAT particles does not allow a more sophisticated treatment of their formation in a 3-D model (see e.g. Knopf et al., 2002). In short, there is no observational evidence to constrain how the nucleation rate might depend on conditions in the vortex. Note that by using a volume-average nucleation rate we are not implying that in reality NAT forms homogeneously throughout the NATsupersaturated region. Particles may be generated in a more localised fashion (e.g. Fueglistaler et al., 2002). Rather, our model calculations therefore represent a situation in which large particles, produced by whatever mechanism, become well distributed (although not necessarily evenly) through the vortex, as observed in January to March 2000 (Northway et al., 2002). The implications of this assumption are discussed in the conclusions section of this paper. It is worth noting that even with this constant volume-average nucleation rate, particle sizes and number densities become spatially very heteorogenous, suggesting a strong controlling influence of the meteorological processes which are studied in this paper.

\section{Winter-long denitrification simulations}

Figures 1a, 3a, 4a and 5a show height-time slices of calculated cumulative denitrification for the winters 1994/95, $1995 / 96,1996 / 97$ and 1999/2000 as a percentage of the passive nitric acid mixing ratio. The denitrification is shown as a vortex average, taken to be the mean over all grid boxes with equivalent latitude greater than $70^{\circ}$. Equivalent latitude is a potential vorticity-normalized latitude, with the vortex cen- tre having an equivalent latitude of $90^{\circ}$ and the vortex edge having a constant equivalent latitude (Nash et al., 1996).

In each figure, alongside the denitrification are also shown a number of related quantities. In panel (b) the area of the NAT-supersaturated region is shown, i.e. the area where $T<T_{\mathrm{NAT}}$, using the expression of Hanson and Mauersberger (1988) and the modelled total $\mathrm{HNO}_{3}$ (not the passive $\mathrm{HNO}_{3}$ ). This is the area in which NAT particles can form and grow. In times of strong vortex denitrification, there may be areas which have had concentrations of $\mathrm{HNO}_{3}$ reduced to just 1 or 2 ppbv. In these areas $T_{\mathrm{NAT}}$ will be much reduced and of ten will stay undersaturated with respect to NAT. In panel (c) the NAT region-vortex centroid separation (normalised by the effective radius of the NAT region) is shown. A normalised centroid separation of 1 means that the centroids of the NAT region and vortex are separated by 1 effective NAT region radius. In panel (d) the number density of NAT particles is shown (calculated as an average at each level over all SLIMCAT grid boxes containing particles). Panel (e) shows the evolution of mean particle radius. Finally, panel (f) shows the height-resolved denitrification rate, calculated by considering the NAT particle mass fluxes at each altitude. The mass flux for each NAT particle is calculated from the mass of the particle multiplied by its sedimentation speed, each calculated as in Carslaw et al. (2002). The volume-average mass flux for each SLIMCAT grid box is then calculated. The difference between the mass fluxes entering the top of the box and leaving from below gives an indication of the instantaneous denitrification/nitrification that is occurring. A negative rate means denitrification. Further details of this calculation are given in Appendix B. Calculated mean and maximum values of downward $\mathrm{HNO}_{3}$ flux for 20 January 2000 are around $1 \times 10^{9}$ and $9 \times 10^{9}$ molecules per $\mathrm{cm}^{-3} \mathrm{~km} \mathrm{day}^{-1}$, which compares well with the value reported by Northway et al. (2002b) of $5 \times 10^{9}$ molecules per $\mathrm{cm}^{-3} \mathrm{~km} \mathrm{day}^{-1}$ for that day along the ER-2 flight track.

\subsection{Winter 1999/2000}

Denitrification starts in early December, initially mainly above $500 \mathrm{~K}$, but by the end of December the maximum vortex average denitrification is $35 \%$, with significant denitrification extending from $575 \mathrm{~K}$ to $450 \mathrm{~K}$. By 20 January 2000 , when the first ER-2 observations of large particles and denitrification were made in the SOLVE/THESEO $2000 \mathrm{cam}$ paign, the average vortex denitrification had reached over $65 \%$ (around $10 \mathrm{ppb}$ ) throughout the altitude range 475 to $550 \mathrm{~K}$. Beyond this date, the denitrification increases only a little and the depth of the denitrified region remains approximately constant. A nitrified region is also clearly visible (shown as red in Fig. 1a). Descent of the most denitrified part of the vortex air can also be seen in this and all winters.

In situ measurements of $\mathrm{NO}_{y}$ and $\mathrm{HNO}_{3}$ aboard the ER2 aircraft made in mid-March 2000 showed widespread denitrification had taken place over a large alititude range 


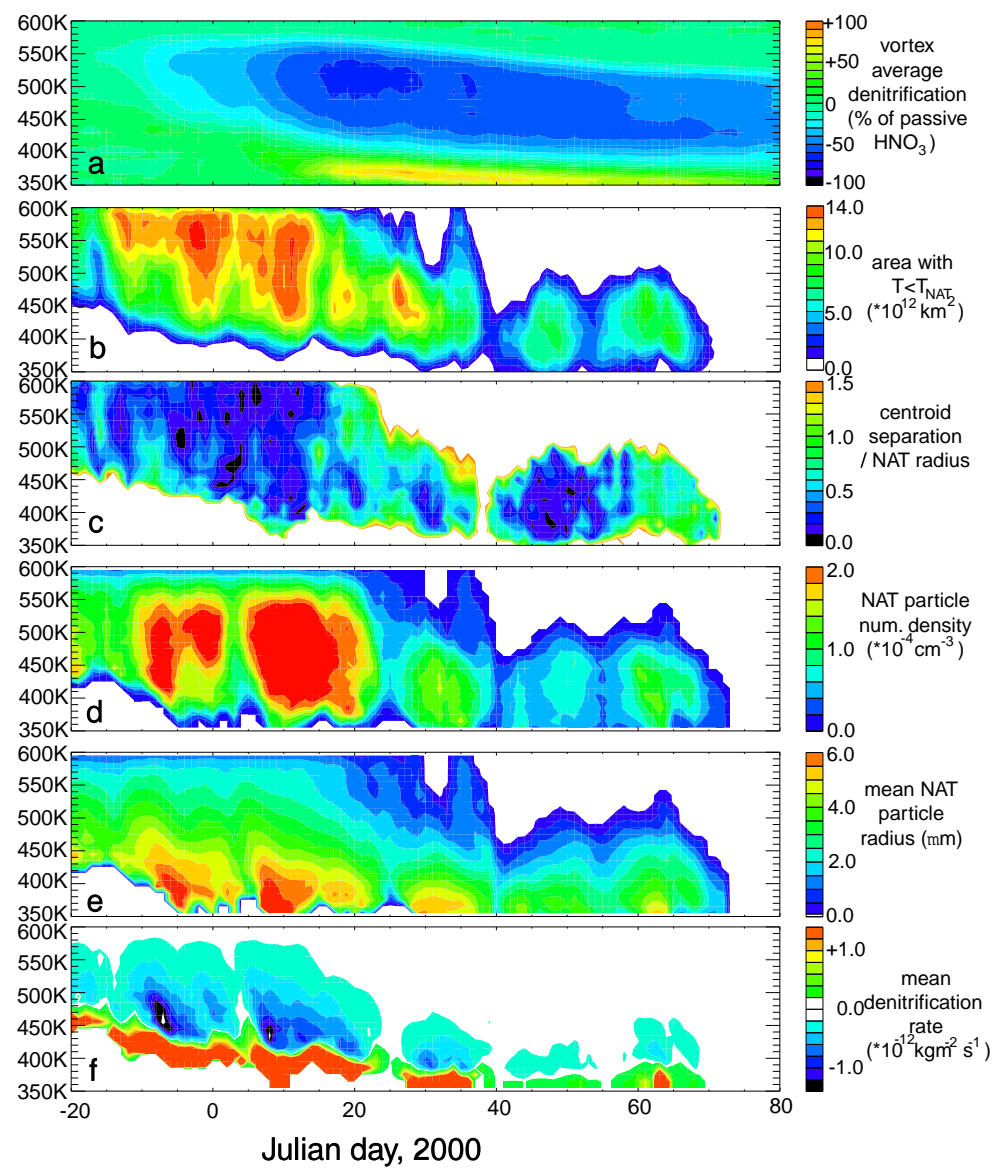

Fig. 1. Altitude-times plots for winter 1999/2000 of (a) vortex average denitrification; (b) area of Arctic stratosphere below $T_{\mathrm{NAT}}$; (c) normalized centroid separation; (d) particle number concentration; (e) mean particle radius; and (f) height-resolved denitrification rate. Vortex average denitrification is calculated from all grid boxes with equivalent latitude $>70$ degrees. Particle number concentration is the mean over all grid boxes containing NAT particles. The centroid separation is normalized by the effective NAT region (where $T<T_{\text {NAT }}$ ) radius. The denitrification rate is calculated as described in Appendix B. compared with early December 1999 (Popp et al., 2001; Kleinböhl et al., 2002). Satellite observations of $\mathrm{HNO}_{3}$ at $465 \mathrm{~K}$ also showed that the denitrification persisted long after temperatures rose above the PSC threshold in early March 2000 (Santee et al., 2000). The denitrification predicted by the model is consistent with both these observations. A more detailed comparison is beyond the scope of this paper, although a paper describing these comparisons is in preparation.

The evolution of substantial modeled denitrification can be related to the NAT area and centroid separation. The NAT area is very large over much of the vortex for about 30 days between 15 December and 15 January and the vortex and NAT region also remain close to concentric over much of the altitude range for the same period (indicated by the low values of centroid separation in Fig. 1c). In other words, during this early winter period the vortex is concentric whenever temperatures are low and the concentric state of the vortex extends from around $475 \mathrm{~K}$ to $600 \mathrm{~K}$. After 15 January the vortex becomes more disturbed and the NAT region-vortex centroid separation increases. It was in this post-January 15 period that all the large nitric acid particle observations were made (Northway et al., 2002a). We have no in situ measure- ments of the evolution of particle sizes and the magnitude of denitrification in the period 15 December to 15 January when conditions were optimum for growth of NAT particles to large sizes.

Figure 1 also shows altitude-time plots of average NAT particle number concentration $N$ (graph d) and mean NAT particle radius $\bar{r}$ (panel e). The largest particles are found in the lowest part of the NAT region where they have had time to grow to larger sizes from their initial nucleation height. Particles at greater altitudes have, on average, not been growing for as long. The model predicts that large NAT particles were present somewhere in the Arctic throughout late December and most of January in the potential temperature range 350 to $450 \mathrm{~K}$. Average model number densities peaked at around $2 \times 10^{-4} \mathrm{~cm}^{-3}$ at around $475 \mathrm{~K}$ on 12 January 2000 and were consistently of the order $10^{-4} \mathrm{~cm}^{-3}$ between 450 and $550 \mathrm{~K}$ in the periods 20-30 December 1999 and around 7-20 January 2000.

Panel (f) shows the height-resolved denitrification rate. The levels where denitrification and nitrification are occurring at any one time are clearly apparent (coloured blue and red respectively). The vast majority of denitrification took place in December and January. Denitrification is predicted 

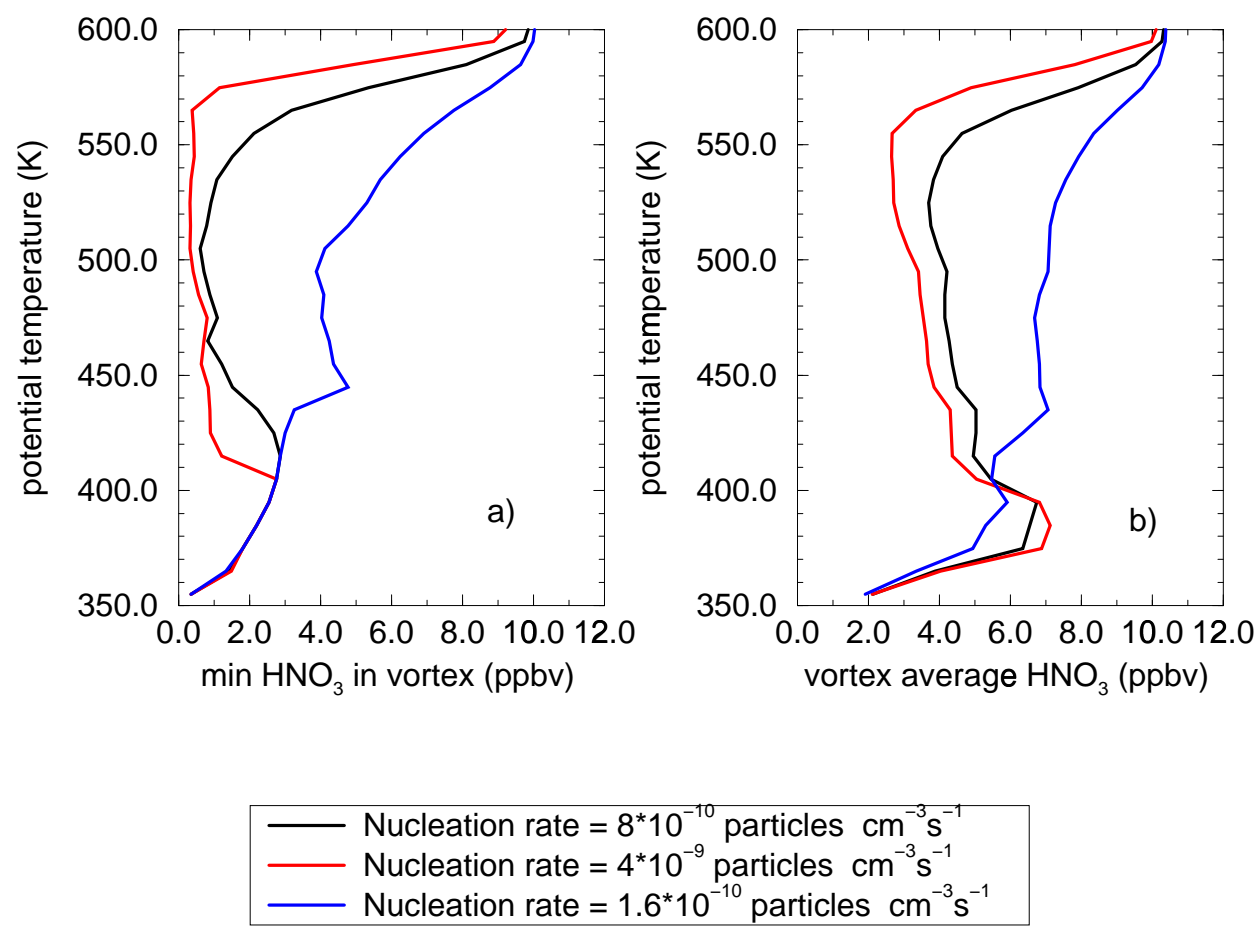

Fig. 2. Model profiles of $\mathrm{HNO}_{3}$ for 20 January 2000 (a) at minimum value inside the vortex and (b) as a vortex average. The black line is for the nucleation rate used in the winter simulations as in Figs. 1, 3, 4 and 5, the red and blue lines are for nucleation rates 5 times higher and lower respectively.

to have been close to saturation (i.e. gas phase $\mathrm{HNO}_{3}$ will have approached the $\mathrm{HNO}_{3}$ vapour pressure over NAT) in much of the vortex by the time the first in situ observations were made on 20 January 2000.

To investigate the sensitivity of the modelled denitrification to the value of the assumed constant nucleation rate (and hence the particle number density), we have repeated the 1999/2000 winter simulations with the nucleation rate increased and decreased by a factor of 5 . Figure 2 shows model profiles of vortex-mean and vortex-minimum $\mathrm{HNO}_{3}$ profiles from 20 January 2000 for these 2 simulations. For the run with the nucleation rate increased by a factor of 5 (the red line in Figs. 2a and b), minimum total nitric acid concentrations are below $1 \mathrm{ppbv}$ at all levels between $430 \mathrm{~K}$ and $560 \mathrm{~K}$ and the vortex average denitrification/nitrification is significantly higher. The higher nucleation rate results in higher number densities (around $10^{-3} \mathrm{~cm}^{-3}$ ) and slightly reduced radii due to the competition for available $\mathrm{HNO}_{3}$. However, Fig. 2 shows that despite this slight decrease in particle radius, the denitrification is still increased by the increase in nucleation rate. This result is broadly in agreement with the 1-D model calculations of Jensen et al. (2002).

When the nucleation rate is decreased by a factor of five (the blue line), the mean denitrification is reduced by about $50 \%$. From this sensitivity simulation, we conclude that the NAT particle number densities and sizes observed in the Jan- uary 2000 vortex (Fahey et al., 2001) are sufficient to almost reduce $\mathrm{HNO}_{3}$ concentrations to the minimum possible. Increases in number density lead to only a small increase in the magnitude of denitrification. On the other hand, decreases in number density lead to significant reductions in the magnitude of denitrification. This sensitivity to number density (and therefore to volume average nucleation rate) makes it important to determine a physical explanation for the NAT particles observed.

\subsection{Winter 1994/95}

The dynamical structure of the 1994/95 vortex is quite different to that of the 1999/2000 winter. Figure 3 shows that the area of NAT supersaturation was generally smaller (in both horizontal and vertical extents) than in 1999/2000. The greatest NAT areas were at lower altitudes. The greatest contrast to the 1999/2000 winter is apparent in the centroid separation. Although there are two short periods with a highly concentric NAT region and vortex (13-20 December and 10-15 January) the vortex is generally much more disturbed, with the NAT region centre displaced away from the centre of the vortex. Mann et al. (2002) showed that such a configuration of the NAT region and vortex reduces the rate of denitrification since particles tend to be advected out of the NAT region before they can grow large enough to sediment rapidly. 


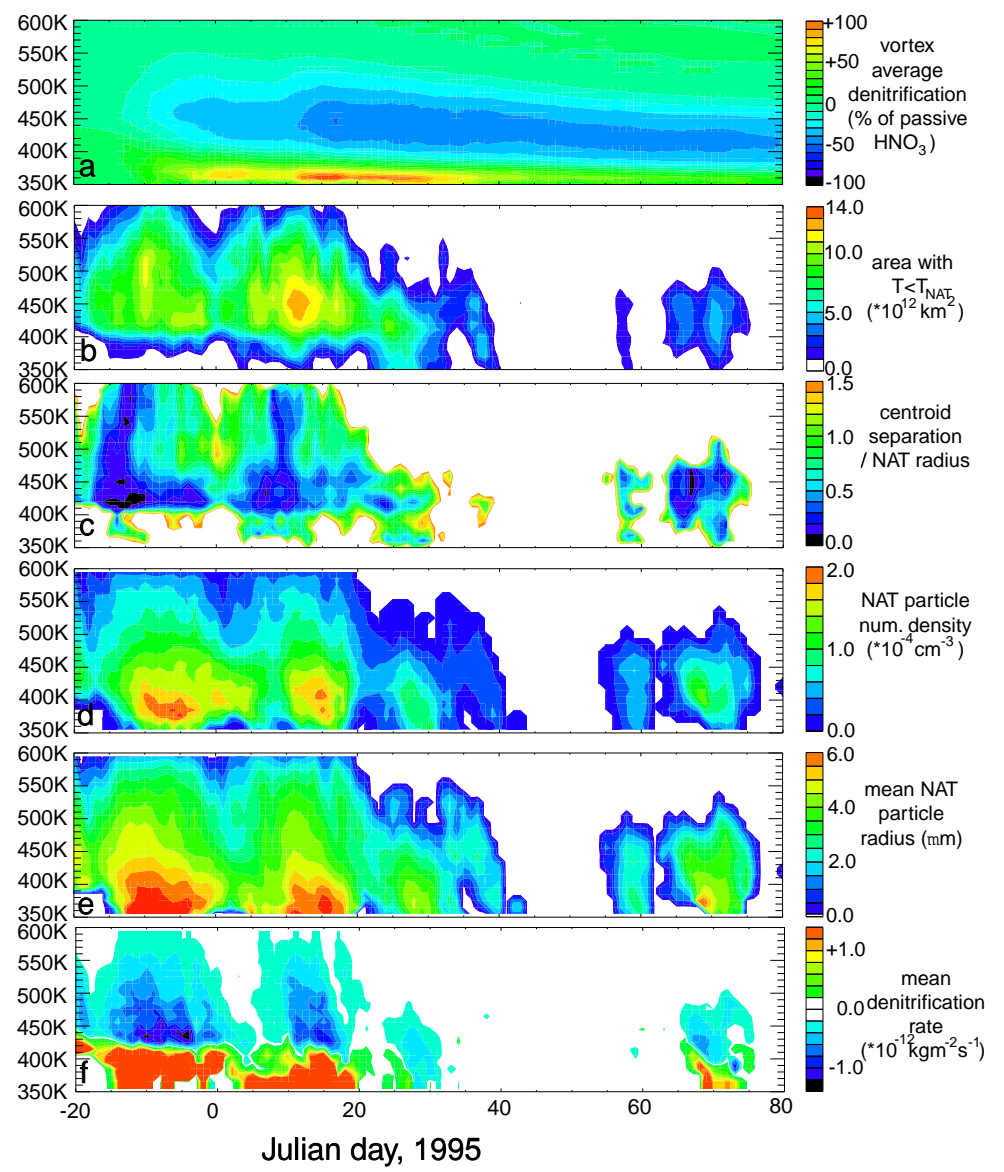

Fig. 3. Altitude time plots for winter 1994/95 of (a) vortex average denitrification; (b) area of Arctic stratosphere below $T_{\mathrm{NAT}}$; (c) normalized centroid separation; (d) particle number concentration; (e) mean particle radius; and (f) denitrification rate.
Denitrification in the model begins after 20 December (after the period of small centroid separation), but increases much more slowly than during the 1999/2000 winter. The predicted vortex-average denitrification reaches a maximum of around $50 \%$ (around $8 \mathrm{ppb}$ ) in a much thinner layer than in 1999/2000 and denitrification is typically lower at around $30-40 \%$, both of which are consistent with the controlling processes outlined above. Although conditions were not optimum for denitrification for much of winter 1994/95, the model still predicts NAT particle populations similar to those observed during 1999/2000 for the two episodes in December 1994 and January 1995 described above.

Waibel et al. (1999) reported that balloon-borne measurements in the Arctic vortex by the MIPAS-B instrument indicated a $50 \% \mathrm{NO}_{y}$ deficit between 16 and $22 \mathrm{~km}$ on 11 February 1995 which once again compares favourably with the modelled denitrification in Fig. 3a.

\subsection{Winter 1995/96}

The 1995/96 winter was very cold at high altitudes (>500 K) with the NAT region reasonably concentric with the vortex (see Fig. 4c) at these altitudes. However, below $500 \mathrm{~K}$ the NAT region centroid was displaced almost to the vortex edge for most of December and January. These periods of high centroid separation coincide with periods of lower NAT areas, and therefore higher temperatures. Significant denitrification is predicted to start only in January 1996, with the peak of the denitrifed layer being above $500 \mathrm{~K}$. The vortex average denitrification reaches a maximum of about $25 \%$ (around $4 \mathrm{ppb}$ ) at $500 \mathrm{~K}$ in January. Only in early February do the vortex and NAT region become nearly concentric over a large altitude range, leading to a further intensification of denitrification to a maximum of around $45 \%$ vortex average (around $8 \mathrm{ppb}$ ) at $450 \mathrm{~K}$.

\subsection{Winter 1996/97}

The 1996/97 winter did not get sufficiently cold to form PSCs until January but stayed very cold well into March, much later than in the other winters (see Fig. 5). In mid to late January, there was quite a large and deep area of NAT supersaturation, but this NAT area was not very concentric with the vortex, so particle number density and mean radius both stayed relatively low giving low downward $\mathrm{HNO}_{3}$ flux and only a small amount of denitrification. By contrast, in February the centroid separation was low, meaning a concentric vortex and NAT region. Between days 35 and 60, this ar- 


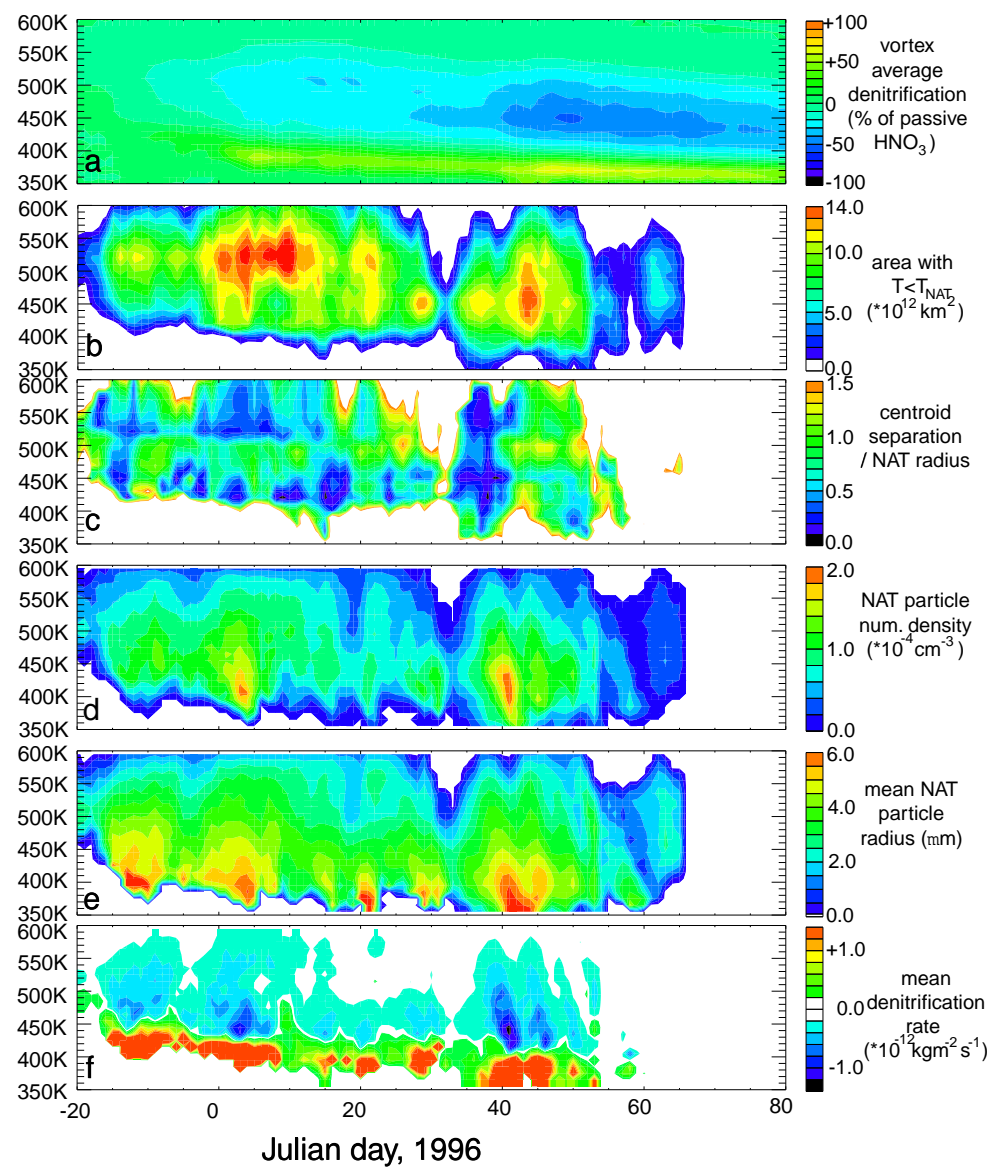

Fig. 4. Altitude time plots for winter 1995/96 of (a) vortex average denitrification; (b) area of Arctic stratosphere below $T_{\mathrm{NAT}}$; (c) normalized centroid separation; (d) particle number concentration; (e) mean particle radius; and (f) denitrification rate.

Table 1. Maximum vortex average denitrification and absolute maximum denitrification in the four cold winters of the 1990s. Also shown are the timing and altitude in each case

\begin{tabular}{ccccccc}
\hline & \multicolumn{3}{c}{ Vortex average denit. } & \multicolumn{3}{c}{ Absolute maximum denit. } \\
\hline Year & $\begin{array}{c}\text { Maximum } \\
(\%)\end{array}$ & $\begin{array}{c}\text { Altitude } \\
(\mathrm{K})\end{array}$ & $\begin{array}{c}\text { Timing } \\
(\mathrm{Jul} . \text { day })\end{array}$ & $\begin{array}{c}\text { Maximum } \\
(\%)\end{array}$ & $\begin{array}{c}\text { Altitude } \\
(\mathrm{K})\end{array}$ & $\begin{array}{c}\text { Timing } \\
(\mathrm{Jul} \text {. day })\end{array}$ \\
\hline $94 / 95$ & 50 & 455 & 17 & 92 & 455 & 2 \\
$95 / 96$ & 52 & 455 & 50 & 78 & 455 & 51 \\
$96 / 97$ & 44 & 455 & 78 & 85 & 465 & 58 \\
$99 / 00$ & 66 & 510 & 21 & 97 & 505 & 21 \\
\hline
\end{tabular}

rangement allowed NAT particles to reach large sizes and to accumulate relatively high number densities causing the region between 430 and $490 \mathrm{~K}$ to become more than $30 \%$ denitrified by the beginning of March.

The satellite borne Improved Limb Atmospheric Spectrometer (ILAS) measured large $\mathrm{NO}_{y}$ deficits inside the polar vortex (Kondo et al., 2000). Denitrification was measured to be as high as $10 \mathrm{ppbv}$ at $490 \mathrm{~K}$ over Baffin Island on 28 February and generally compares well with our modelled denitrification (manuscript in preparation).

\subsection{Overview}

The model calculates moderate to large denitrification in some areas of the Arctic stratosphere for all these four cold winters of the 1990s (see Table 1). In addition, large NAT particles are predicted to occur in each winter. Average number concentrations of particles reach a maximum of about $10^{-4} \mathrm{~cm}^{-3}$, but vary greatly during each winter. Winter $1999 / 2000$ has the highest average number concentrations $\left(\sim 2 \times 10^{-4} \mathrm{~cm}^{-3}\right)$, although these occurred before the ER-2 in situ observations (Fahey et al., 2001).

Figure 6 shows histograms of the calculated denitrifica- 


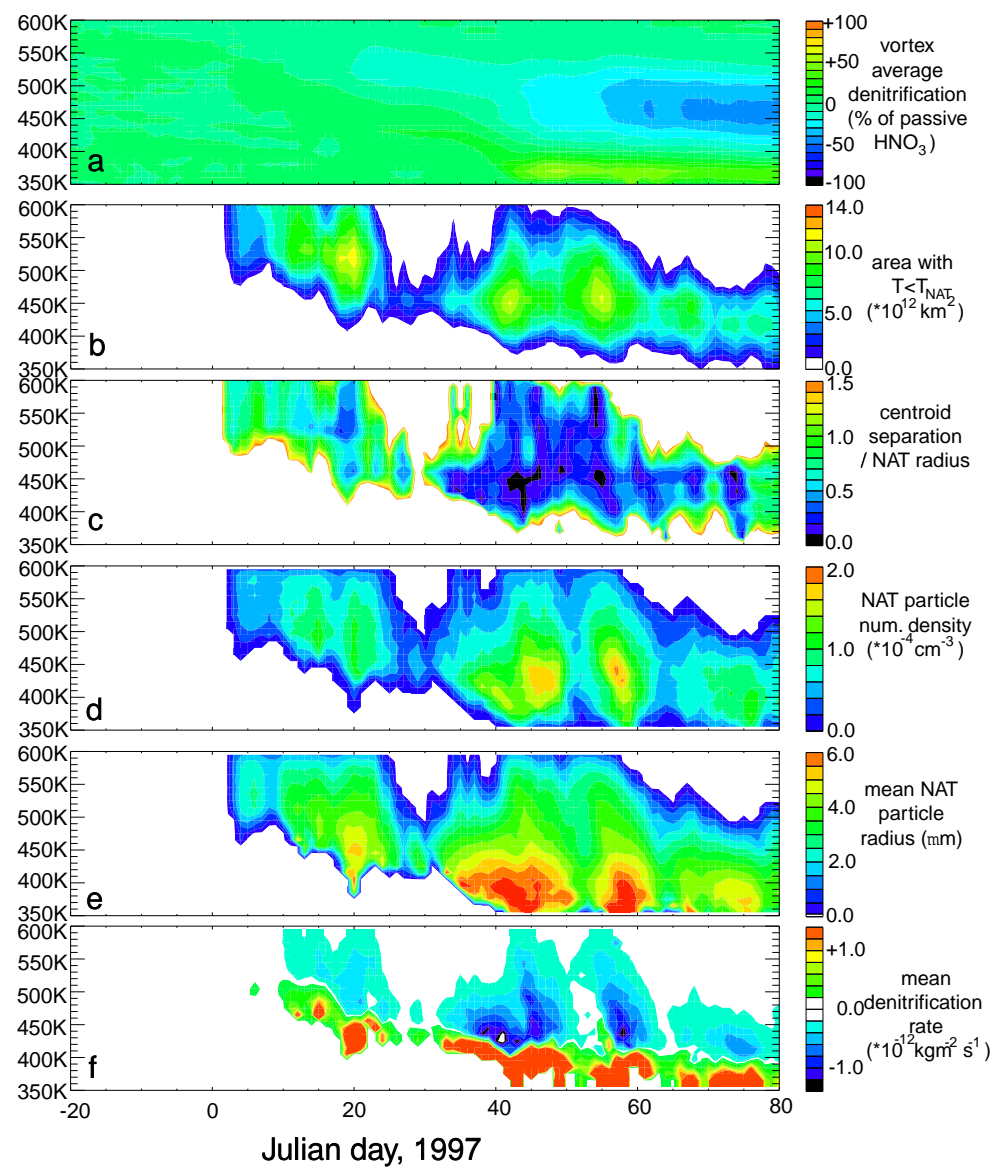

Fig. 5. Altitude time plots for winter 1996/97 of (a) vortex average denitrification; (b) area of Arctic stratosphere below $T_{\mathrm{NAT}}$; (c) normalized centroid separation; (d) particle number concentration; (e) mean particle radius; and (f) denitrification rate.

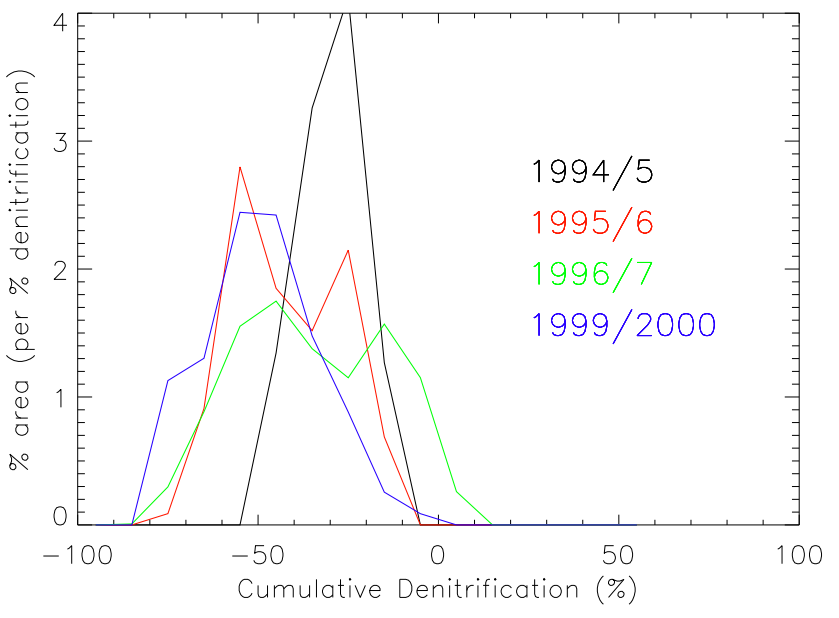

Fig. 6. Percentage area histograms of $\%$ denitrification at $465 \mathrm{~K}$ on 28 February of 1995, 1996, 1997 and 2000.

tion on the $475 \mathrm{~K}$ level on 28 February for each of the years. These give an indication of the variation of the denitrification about the mean. There is great variability in the magnitude and range of denitrification in the vortex. Winter 1994/95 shows moderately denitrified air with a narrow range while winters 1995/96 and 1996/97 have bimodal distributions of denitrification, with some air being only slightly denitrified and other air being quite strongly denitrified. This bi-modal distribution can be explained by the timing of the denitrification in these winters, with recent denitrification not having time to mix. Winter 1999/2000 has the strongest and most widespread denitrification at this time and altitude.

\section{Factors controlling denitrification}

\subsection{What the simulations tell us}

These model simulations show that a number of factors control the magnitude of denitrification by low number concentrations of NAT particles. Denitrification depends on the development of populations of large NAT particles over several days. These particles can grow (or evaporate), sediment, and are advected by the wind over several days, so the dependence of denitrification on meteorology is therefore complex. The nucleation mechanism of NAT particles is very uncertain, hence these simulations have used the simplest ap- 


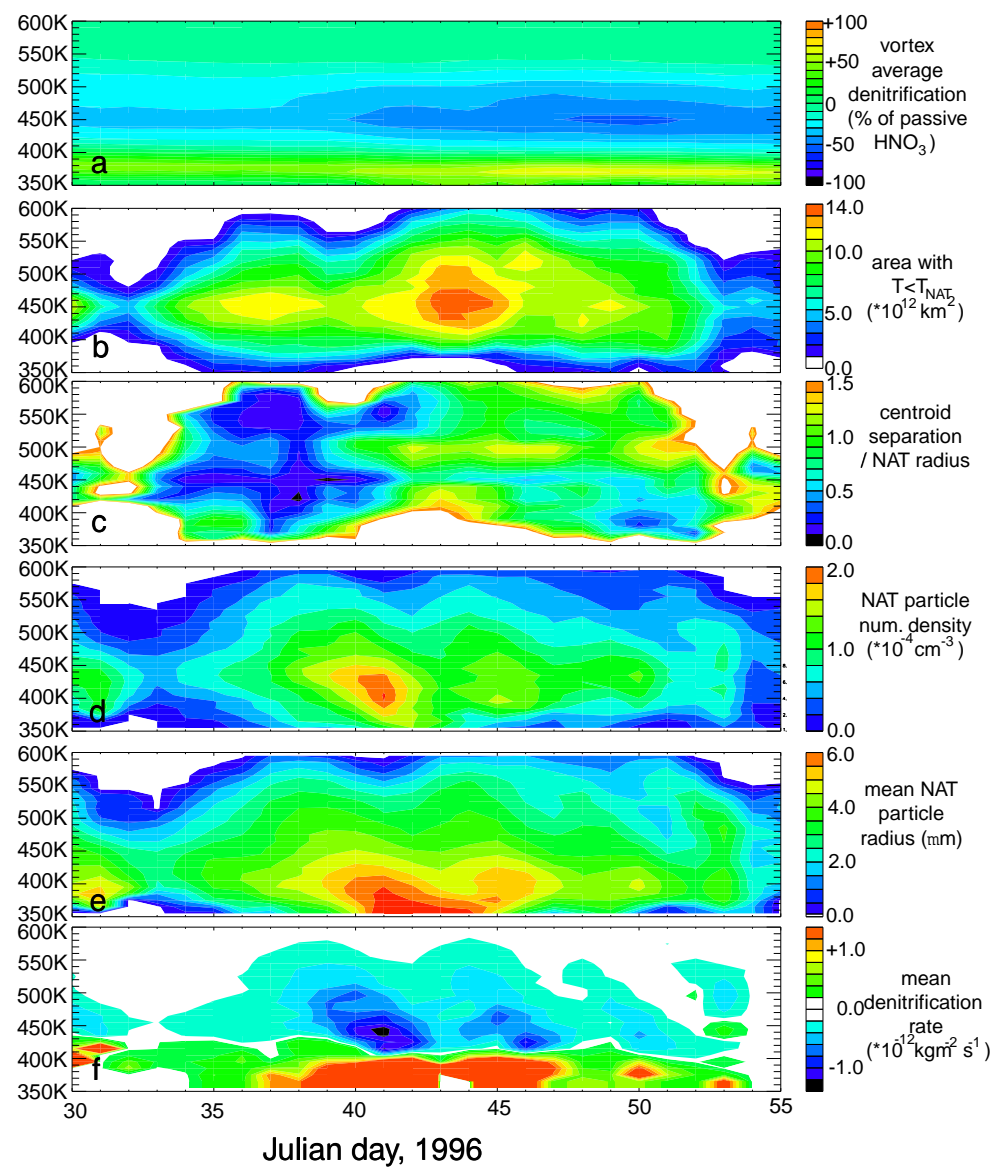

Fig. 7. Altitude time plots for February 1996 of (a) vortex average denitrification; (b) area of Arctic stratosphere below $T_{\mathrm{NAT}}$; (c) normalized centroid separation; (d) particle number concentration; (e) mean particle radius; and (f) difference in incoming and outgoing downward NAT mass flux. Further details as in caption to Fig. 1. This figure shows more clearly the controlling influence of vortex/NAT region concentricity on denitrification. proach - namely to nucleate particles at a constant volumeaverage rate as soon as $T$ is less than $T_{\mathrm{NAT}}$.

An examination of Figs. 1, 3, 4 and 5 suggests that during some periods the NAT area is a good indicator of denitrification rate (panel f), while at other times the NAT region-vortex centroid separation is better. For example, NAT area appears to drive the denitrification rate between days 40 and 60 in 1996/7 (Fig. 5) during a period with low centroid separation. In contrast, the centroid separation seems to drive the denitrification rate between days 35 and 45 in 1995/6 (Fig. 4).

Figure 7 shows this latter period in more detail. On day 35 a reasonably large NAT-supersaturated region forms which is concentric with the polar vortex. On day 41, this region begins to get larger and deeper to a maximum on day 44 . However, as it does so, its centre moves towards the edge of the polar vortex (the centroid separation increases) and consequently the particle number density reduces by around $50 \%$ and the mean radius also reduces noticeably. The lowest panel shows how, in this instance, the denitrification is controlled by the concentricity of the vortex despite the increase in the size of the NAT region.

Note that neither the NAT area nor the centroid separation would control the denitrification rate in a model in which the particles were in equilibrium with the gas phase (Mann et al., 2002). The denitrification rate in panel (f) is calculated as per unit area of the region which contains particles, so making the NAT area bigger does not influence this rate (although it would of course, if calculated as a vortex average). The dependence of denitrification rate on NAT area and centroid separation therefore reflects a sensitivity to Arctic meteorology arising from the time-dependent growth of the NAT particles.

4.2 Concept of "closed-flow" and "through-flow" as indicators of potential denitrification

The NAT area and the concentricity of the NAT region and vortex both act together to control the temperature trajectories of the particles. The dependence of the denitrification rate on the centroid separation is clear: Mann et al. (2002) showed that a concentric NAT area and vortex allows particles to grow over several days, reaching large sizes and inducing a high downward $\mathrm{HNO}_{3}$ flux. Thus, a concentric NAT area and vortex creates a region of air which is in "closed-flow" in which particles can circulate and grow (and ultimately sediment) in the NAT area for several days. The reason for the dependence of the denitrification rate on NAT 

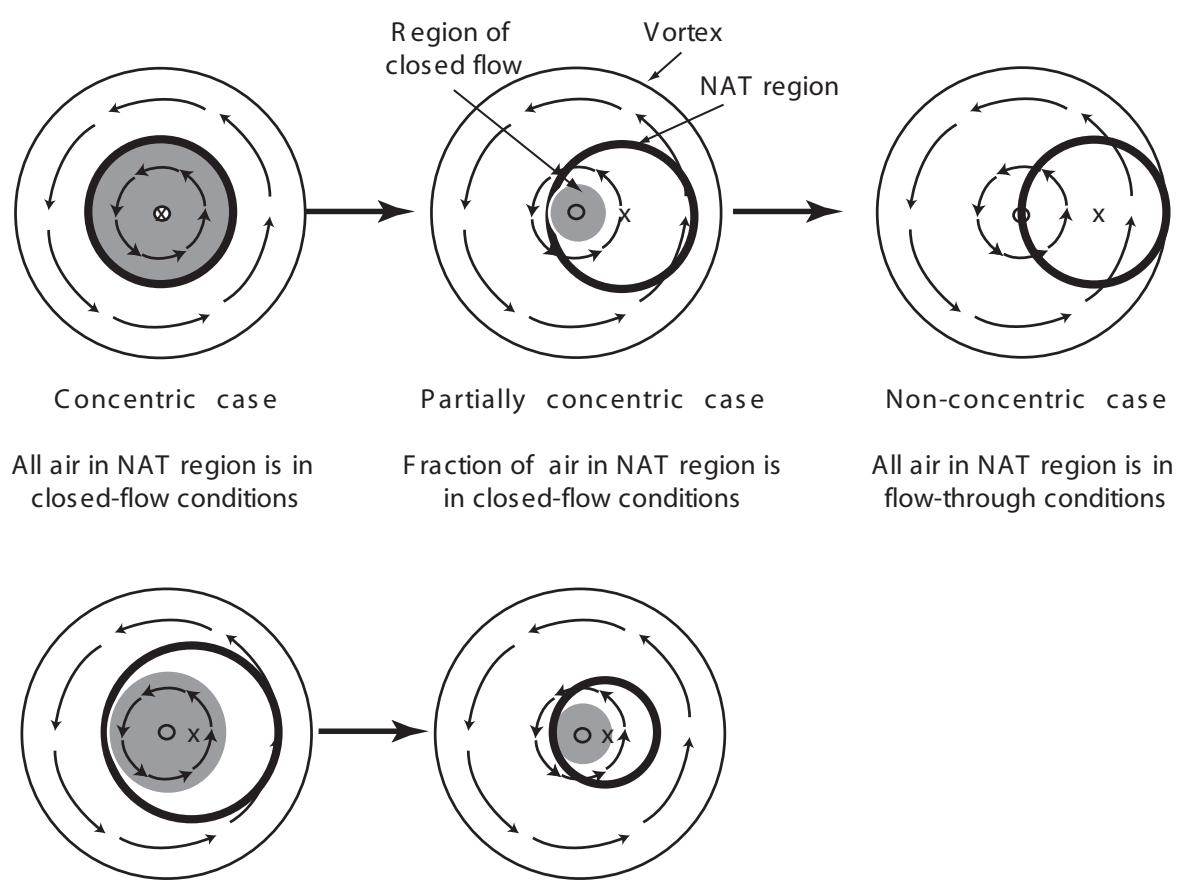

Fig. 8. Schematic of how the NAT area-vortex centroid separation and the NAT area area control the denitrification rate. The "closed-flow" region is shaded. (a) The effect of shifting the NAT area away from the centre of the vortex; (b) the effect of reducing the size of the NAT area.

supersaturated area is not so immediately obvious. It arises because the size of the NAT area also determines the region of the NAT area with closed-flow.

Figure 8 shows schematically how the NAT area-vortex concentricity and the NAT area control denitrification. In panel (a) an inititially concentric NAT region and vortex creates a large region of air in closed-flow (shaded region) in which particles can circulate for several days and grow to large sizes. As the NAT area (with constant size) is shifted away from the vortex centre, the region of closedflow shrinks. Panel (b) shows that maintaining a fixed relative position of the NAT area and vortex but reducing the size of the NAT area also has the effect of reducing the area with closed-flow.

The potential for denitrification is a maximum in the region of closed-flow and, although not zero, the rate of denitrification is likely to be much lower in the "through-flow" region where NAT particles can grow for a shorter time. The denitrification rate depends in a very nonlinear way on the time available for growth, $t$ (Carslaw et al., 2002). The particle mass increases with $t^{3 / 2}$ and the fall distance increases with $t^{2}$. In addition, assuming a constant nucleation rate, particle number concentrations will increase with $t$. This equates to a very strong dependence of denitrification rate on the time available for growth, such that the closed-flow region will dominate denitrification.

We can test this hypothesis by plotting the denitrification rate against the fraction of the NAT area that is in closed-flow.
This fraction, $c_{\text {flow }}$ is calculated as follows

$c_{\text {flow }}=\frac{\left(r_{\mathrm{NAT}}-c\right)^{2}}{r_{\mathrm{NAT}}^{2}}$

where $r_{\mathrm{NAT}}$ is the NAT area radius and $c$ is the separation of the NAT area and vortex centroids. Note that this fraction of the NAT area which is in closed-flow assumes circleequivalent radii. In addition, areas of the vortex can develop containing a very low mixing ratio of $\mathrm{HNO}_{3}$, so although the NAT area may be large and be mostly in closed-flow, there may be no supply of $\mathrm{HNO}_{3}$ available to form the large NAT particles and the denitrification will be lower than expected. Figure 9 shows a plot of the mean of denitrification rate against the mean of the closed-flow fraction $c_{\text {flow. }}$. Both of these means are calculated over all levels between $350 \mathrm{~K}$ and $600 \mathrm{~K}$ excluding net nitrification layers. Note that by taking the mean in this way, we also include to some extent, the effect of the depth of the closed-flow region because levels which have a NAT region completely in through-flow (or no NAT region at all) will have $c_{\text {flow }}=0$ and hence the mean of the closed-flow fraction over all these levels will be lowered. The denitrification rate has been normalised by dividing the denitrification rate by the amount of available $\mathrm{HNO}_{3}$ in each grid box (see Appendix B). Also shown is a line plot indicating the mean and standard deviation of the denitrification rate The $y$ value of each point is the denitrification rate calculated with a 3 day time lag relative to the $x$ axis. The existence of 


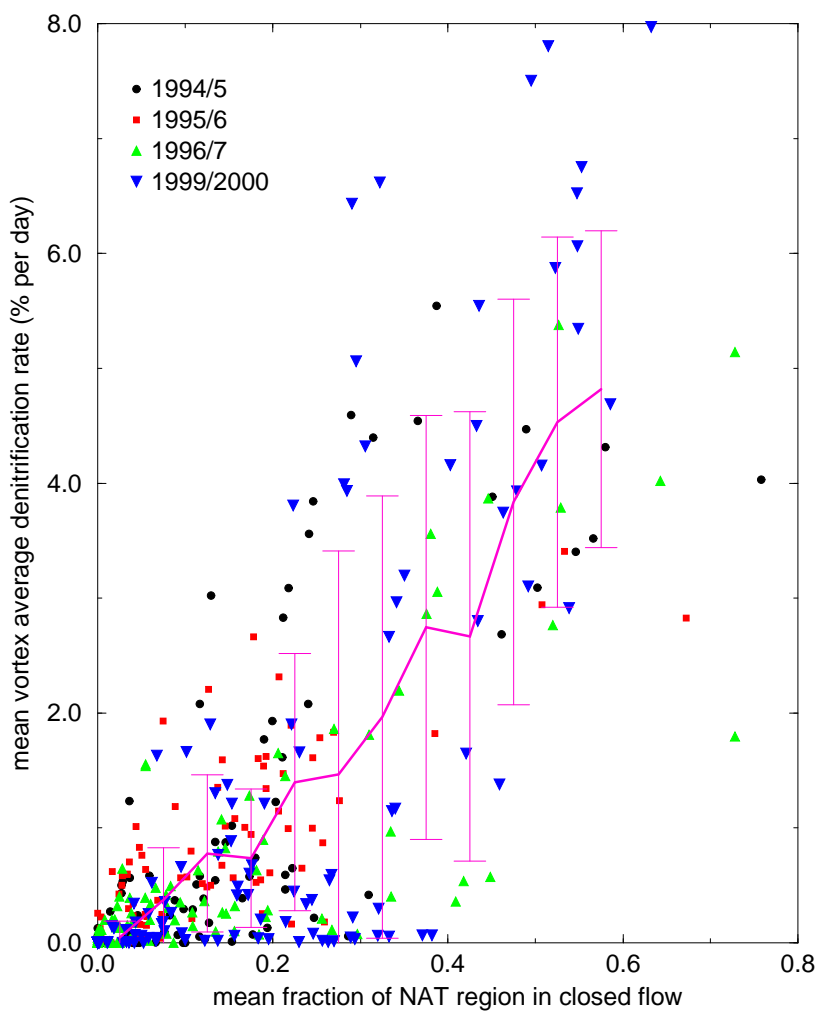

Fig. 9. The mean denitrification rate as a function of the mean fraction of the NAT area in which closed-flow can occur. Details of the calculation of denitrification rate are given in Appendix B.

this time lag can be seen from the tilt evident in the instantaneous denitrification rate plots in Figs. 7d-f.

Although there is quite a large amount of scatter in Fig. 9, the overall pattern is clear. For situations where the NAT region is mainly in closed-flow, the denitrification rate is much higher than more disturbed situations when the closed-flow fraction is low. Only the part of the NAT area in closed-flow has conditions conducive to the production of large NAT particles which are efficient at denitrification. The maximum mean normalized denitrification rate for periods in which all NAT-supersaturated air was in through flow (i.e. no closedflow in the NAT area at any height) was $0.13 \%$ per day, which is about 30 times lower than the mean value when half or more of the NAT area is in closed-flow.

A number of factors have combined to cause the large scatter in Fig. 9. Firstly, when the vortex becomes elongated, the actual closed-flow area can be significantly smaller (or larger) than predicted by assuming circular geometry. This introduces scatter in the plot. Secondly, as we have seen, the fraction of NAT area which has closed-flow can vary in complicated ways in the vertical, hence a straightforward mean in the vertical adds further scatter. Thirdly, the timescale of dynamical changes in the vortex is similar to the timescale of changes in particle sizes and number concentrations. It takes around 8 days for a steady particle population to be generated (Carslaw et al., 2002; Mann et al., 2002) so any change in the vortex-NAT region arrangement during that time can complicate the relationship between closed-flow area and denitrification rate even further. Future studies could perhaps examine the actual area of closed-flow derived from the flow fields, rather than using an assumption of circular geometry for the NAT area and vortex.

The rather complicated dependence of denitrification rate on vortex dynamics means that denitrification is not easy to parameterise. A large area of closed-flow in the NAT area is a pre-requisite for rapid denitrification, but the actual rate of denitrification can be reduced by a number of factors. However, it is worth noting again, that as shown in Mann et al. (2002), an increase in denitrification rate with closed-flow fraction would not be reproduced in a model that assumed equilibrium between the particles and the gas phase. This is an additional sensitivity that arises from the non-linear growth and sedimentation behaviour of the particles. The vortex-average denitrification will depend additionally on the fraction of the vortex with temperatures below $T_{\mathrm{NAT}}$, but this will be a linear dependence.

\section{Conclusions}

Our analysis shows that denitrification could have occurred in previous cold winters with low volume-average NAT nucleation rates similar to those derived for winter 1999/2000. However, the magnitude of denitrification in winter 1999/2000 was significantly greater than in many previous cold winters because the vortex dynamics were optimum. These optimum conditions are a deep NAT area positioned towards the centre of the vortex, which allows for long NAT particle lifetimes. Long lifetimes allow particles to reach large sizes, which increases their fall speed (proportional to radius squared) as well the amount of nitric acid sequestered in the particles. In addition, the dynamical conditions that lead to long particle lifetimes also allow particles to accumulate in the NAT area over several days, while shorter lifetimes are consistent with a higher loss rate of particles. Thus, particle number concentration, size, and fall speed (and hence downward $\mathrm{HNO}_{3}$ flux) are all increased when the NAT area and vortex are concentric.

The reliability of the calculated denitrification depends primarily on the assumption of a constant volume-average NAT particle formation rate in each of the four winters. We have assumed that some process, as yet unidentified, generates low number concentrations of NAT particles throughout the NAT supersaturated region. The constant NAT formation rate that we have used produces particle number densities in good agreement with observations over a 2 month period during winter 2000 (Carslaw et al., 2002). This good agreement suggests that much of the variability in particle populations (and hence denitrification) might be controlled by 
the subsequent vortex-scale evolution of particles after formation, rather than just by the nucleation rate. Particle evolution is well treated in our model, being controlled largely by the variable dynamic structure of the polar vortex, NAT area location, etc. These processes alone give rise to a large degree of variability in particle populations and denitrification rate in different winters, and even within a single winter. An example of this was described in Sect. 4.1. Any meteorologically induced variation in nucleation rate will add to this variability.

Although our volume-average formation mechanism produces good agreement with particle concentrations and sizes wherever these were observed, it should be noted that it also produces particles where none were observed. Further comparisons with observations of the type undertaken by Carslaw et al. (2002) need to be undertaken to see whether an alternative particle formation mechanism can significantly improve on the simple scheme we have so far used. Such comparisons should also be extended to winters other than 1999/2000 in light of the uniqueness of this winter identified here.

An analysis of Arctic vortex concentricity for 10 winters (1984/85 to $1993 / 94)$ by Pawson et al. (1995) shows that highly concentric vortices occur for at least a short period in most cold winters, although not always synchronous with the lowest temperatures. During this 10 year period, 1988/89 and $1989 / 90$ stand out as potentially vulnerable to denitrification similar to that observed in 1999/2000, since they had long periods of low temperatures with a concentric vortex. Indeed, Fahey et al. (1990) observed significant denitrification of the Arctic in February 1989. Examination of the Pawson et al. (1995) analyses and inclusion of more recent observations suggests that optimum conditions for intense Arctic denitrification occur about 3 times per decade. It would be interesting to investigate what meteorological conditions are likely to produce prolonged cold closed-flow. In a future, colder stratosphere for instance, would a cold concentric vortex be more likely to occur? It should also be noted that a prolonged concentric vortex may, conversely, lead to reduced ozone loss since the proportion of the vortex which receives sunlight is likely to be reduced. A cold concentric vortex in early and mid-winter causing widespread denitrification and a more disturbed vortex later in the winter may be optimum for ozone loss.

Finally, we have defined a quantity which we call the "closed-flow area" that is a good indicator of likely denitrification. The closed-flow area, or fraction of the NAT area in which air parcels form closed loops, captures simultaneously the sensitivity of modelled denitrification to NAT area and NAT area-vortex concentricity. Our calculations show that the denitrification rate increases substantially as soon as some of the NAT area contains air in closed-flow.

Our simulations demonstrate that previous cold Arctic winters were susceptible to denitrification by low number concentrations of NAT particles. We have also identified meteorological factors that control the denitrification rate. Fur- ther investigations are required to test these model simulations against observations during past and future Arctic winters.

\section{Appendix A: Particle growth in the microphysical model}

Particle growth is calculated in the microphysical model as in Carslaw et al. (2002) by comparing the ambient $\mathrm{HNO}_{3}$ partial pressure $p_{\mathrm{HNO}_{3}}$ with the saturation $\mathrm{HNO}_{3}$ vapour pressure over NAT $p_{\mathrm{HNO}_{3}}^{\mathrm{NAT}}$ :

$$
\begin{aligned}
\frac{d r}{d t} & =\frac{G}{r}, \\
G & =\frac{D_{\mathrm{HNO}_{3}}^{*} M_{\mathrm{NAT}}}{\rho_{\mathrm{NAT}} R T}\left(p_{\mathrm{HNO}_{3}}-p_{\mathrm{HNO}_{3}}^{\mathrm{NAT}}\right) .
\end{aligned}
$$

The modified diffusion coefficient $D_{\mathrm{HNO}_{3}}^{*}$ is given by

$$
D_{\mathrm{HNO}_{3}}^{*}=\frac{D_{\mathrm{HNO}_{3}}}{1+4 D_{\mathrm{HNO}_{3}} /\left(\bar{c}_{\mathrm{HNO}_{3}} r\right)},
$$

where $D_{\mathrm{HNO}_{3}}$ is the diffusion coefficient of $\mathrm{HNO}_{3}$ in air and $\bar{c}_{\mathrm{HNO}_{3}}$ is the mean molecular speed. The expression of Hanson and Mauersberger (1988) is used to calculate $p_{\mathrm{HNO}_{3}}^{\mathrm{NAT}}$.

\section{Appendix B: Calculation of height-resolved denitrifica- tion rate}

The height-resolved rate of denitrification in each grid box is calculated as the difference in mass flux of NAT falling into and out of that grid box. The NAT mass flux is first calculated in each grid box as the sum over all particles of mass $m$ in the grid box multiplied by their fall velocity $w_{f}$.

$m(r)=\frac{4}{3} \pi \rho_{\mathrm{NAT}} r^{3}$

$w_{f}(r, T, p)=\left(\frac{2 g \rho_{\mathrm{NAT}} C_{C}}{9 v}\right) r^{2}$

where $\rho_{\text {NAT }}$ is the NAT crystal mass density $=1.6 \times 10^{3}$ $\mathrm{kgm}^{-3}, C_{C}$ is the Cunningham slip correction factor,

$C_{C}=1+\frac{\lambda}{r}\left[1.257+0.4 \exp \left(\frac{-1.1 r}{\lambda}\right)\right]$,

where $\lambda$ is the mean free path of $\mathrm{HNO}_{3}$ molecules. The volume-averaged mass flux of NAT $F_{\mathrm{NAT}}$ in $\mathrm{kgm}^{-2} \mathrm{~s}^{-1}$ in each grid box is then found by dividing the grid box mass fluxes by the grid box volume. This volume-averaged flux can also be converted into units of molecules of $\mathrm{HNO}_{3} \mathrm{~cm}^{-3}$ $\mathrm{km} \mathrm{day}^{-1}$ to compare with the values quoted in Northway et al. (2002b) by multiplying by Avogadro's constant and dividing by the molecular weight of NAT (see Sect. 3). A volumeaveraged mass flux $\bar{F}_{\text {NAT }}$ over all grid boxes which contain particles is then calculated at each $\theta$ level. 
It is this difference between incoming and outward values of this flux which is then used to calculate the height-resolved denitrification rate $\frac{d M}{d t}$ shown in panel (f) of Figs. 3, 4, 5 and 1:

$$
\begin{aligned}
& \frac{d M}{d t} \\
& =\frac{\bar{F}_{\mathrm{NAT}}\left(\theta_{j-1}\right) V_{\mathrm{NAT}}\left(\theta_{j-1}\right)-\bar{F}_{\mathrm{NAT}}\left(\theta_{j+1}\right) V_{\mathrm{NAT}}\left(\theta_{j+1}\right)}{V_{\mathrm{NAT}}\left(\theta_{j}\right)},
\end{aligned}
$$

where $V_{\mathrm{NAT}}$ is the total volume at that level which contains NAT particles.

A normalized denitrification rate can also be calculated which accounts for how much $\mathrm{HNO}_{3}$ is available in the gas phase. This normalized rate is calculated as a $\%$ of (molecules of) available $\mathrm{HNO}_{3}$ per day. To calculate how much denitrification is taking place at any level, we take the divergence of the downward flux ( $F_{\mathrm{NAT}}$ having units of molecules of $\mathrm{HNO}_{3} \mathrm{~cm}^{-3} \mathrm{~km} \mathrm{day}^{-1}$ ) in each grid box. We then calculate the source or sink of $\mathrm{HNO}_{3}$ caused by denitrification in molecules of $\mathrm{HNO}_{3} \mathrm{~cm}^{-3}$ day $^{-1}$ and the total number density of molecules of gas phase $\mathrm{HNO}_{3}$ in each grid box. Dividing the flux divergence by the number density of gas phase $\mathrm{HNO}_{3}$ and mutiplying by $100 \%$ then gives the normalized denitrification rate in each grid box in \% per day. The mean normalized denitrification rate at each potential temperature level can then be found by taking the volumeaverage of the normalized denitrification rate over all grid boxes in the NAT region which are not nitrifying.

Acknowledgements. This work was funded by the European Commission, EC, Fifth Framework Program MAPSCORE project, EVK2-CT-2000-00072 and by a NERC studentship.

\section{References}

Carslaw, K. S., Luo, B. P. and Peter, T.: An analytic expression for the composition of aqueous $\mathrm{HNO}_{3}-\mathrm{H}_{2} \mathrm{SO}_{4}$ stratospheric aerosols including gas-phase removal of $\mathrm{HNO}_{3}$, Geophys. Res. Lett., 22, 1877-1880, 1995.

Carslaw, K. S., Kettleborough, J., Northway, M. J., Davies, S., Gao, R.-S., Fahey, D. W., Baumgardner, D. G., Chipperfield M. P., and Kleinböhl, A.: A vortex-scale simulation of the growth and sedimentation of large nitric acid particles observed during SOLVE/THESEO 2000, J. Geophys. Res., 107 (D20), 8300, doi 10.1029/2001JD000467, 2002.

Chipperfield, M. P.: Multiannual simulations with a threedimensional chemical transport model, J. Geophys. Res., 104, 1781-1805, 1999.

Davies, S., Chipperfield, M. P., Carslaw, K. S., et al.: Modeling the effect of denitrification on Arctic ozone depletion during winter 1999/2000, J. Geophys. Res., 107, 8322, doi 10.1029/2001JD000445, 2002, printed 108(D5), 2003.

Deshler, T. and Oltmans, S. J.: Vertical profiles of volcanic aerosol and polar stratospheric clouds above Kiruna, Sweden: Winters 1993 and 1995, J. Atmos. Chem., 30, 11-23, 1998.
Dessler, A. E., Wu, J., Santee M. L., and Schoeberl, M. R.: Satellite observations of temporary and irreversible denitrification, J. Geophys. Res., 104, 13 993-14 002, 1999.

Drdla, K., Schoeberl, M. R., and Browell, E. V.: Microphysical modelling of the 1999-2000 Arctic winter: 1. Polar stratospheric clouds, denitrification, and dehydration, J. Geophys. Res., 107, 8312, doi: 10.1029/2001JD000782, 2002. printed 108(D5), 2003.

Dye, J. E., Baumgardner, D., Gangrud, B. W., et al.: Particle size distributions in Arctic polar stratospheric clouds, growth and freezing of sulphuric acid droplets and implications for cloud formation, J. Geophys. Res., 97, 8015-8034, 1992.

Fahey, D. W., Kelly, K. K., Kawa, S. R., Tuck, A. F., Loewenstein, M., Chan, K. R., and Heidt, L. E.: Observations of denitrification and dehydration in the winter polar stratospheres, Nature, 344, 321-324, 1990.

Fahey, D. W., Gao, R. S., Carslaw, K. S., et al.: The detection of large $\mathrm{HNO}_{3}$-containing particles in the winter arctic stratosphere and their role in denitrification, Science, 291, 1026-1031, 2001.

Fueglistaler, S., Luo, B. P., Voigt, C., Carslaw, K. S., and Peter, T. NAT-rock formation by mother clouds: a microphysical model study, Atmos. Chem. Phys., 2, 93-98, 2002.

Hanson, D. and Mauersberger, K.: Laboratory studies of the nitric acid trihydrate: Implications for the south polar stratosphere, Geophys. Res. Lett., 15, 855-858, 1988.

Hintsa, E. J., Newman, P. A., Jonsson, H. H., et al.: Dehydration and denitrification in the Arctic polar vortex during the 19951996 winter, Geophys. Res. Lett., 25, 501-504, 1998.

Irie, H., Koike, M., Kondo, Y., Bodeker, G. E., Danilin, M. Y., and Sasano, Y.: Redistribution of nitric acid in the Arctic lower stratosphere during the winter of 1996/1997, J. Geophys. Res. 106, 23 139-23 150, 2001.

Jensen, E., Toon, O. B., Tabazadeh, A., and Drdla, K.: Impact of polar stratospheric cloud particle composition, number density, and lifetime on denitrification, J. Geophys. Res., 107(D20), 8284, doi:101.1029/2001JD000440, 2002.

Kleinböhl, A., Bremer, H., von Konig, M., et al.: Vortexwide denitrification of the Arctic polar stratosphere in winter 1999/2000 determined by remote observations, J. Geophys. Res., 8305, doi: 10.1029/2001JD001042, 2002, printed 108(D5), 2003.

Knopf, D. A., Koop, T., Luo, B. P., Weers U. G., and Peter, T.: Homogeneous nucleation of NAD and NAT in liquid stratospheric aerosols: insufficient to explain denitrification, Atmos. Chem. Phys., 2, 207-214, 2002.

Kondo, Y., Irie, H., Koike, M., and Bodeker, G. E.: Denitrification and nitrification in the Arctic stratosphere during the winter of 1996-1997: Geophys. Res. Lett., 27, 337-340, 2000.

Mann, G. W., Davies, S., Carslaw, K. S., Chipperfield, M. P., and Kettleborough, J.: Polar vortex concentricity as a controlling factor in Arctic denitrification, J. Geophys. Res., 107 (D22), 4663, doi 10.1029/2002JD002102, 2002.

Nash, E. R., Newman, P. A., Rosenfield, J. E., and Schoeberl, M R.: An objective determination of the polar vortex using Ertel's potential vorticity, J. Geophys. Res., 101, 9471-9478, 1996.

Northway, M. J., Gao, R. S., Popp, P. J., et al.: An analysis of large $\mathrm{HNO}_{3}$-containing particles sampled in the Arctic stratosphere during the winter of 1999-2000, J. Geophys. Res., 107(D20), 8289, doi:10.1029/2001JD001079, 2002a.

Northway, M. J., Popp, P. J., Gao, R.-S., Fahey, D. W., Toon, G. C., 
and Bui, T. P.: Relating inferred $\mathrm{HNO}_{3}$ flux values to the denitrification of the 1999/2000 Arctic vortex, Geophys. Res. Lett., 29, 63, 1-4, 2002b.

Pawson, S., Naujokat, B., and Labitzke, K.: On the polar stratospheric cloud formation potential of the northern stratosphere, J. Geophys. Res., 100, 23 215-23 225, 1995.

Popp, P. J., Northway, M. J., Holecek, J. C., et al.: Severe and extensive denitrification in the 1999-2000 Arctic winter stratosphere, Geophys. Res. Lett., 28, 2875-2878, 2001.

Prather, M. J.: Numerical advection by conservation of secondorder moments, J. Geophys. Res., 91, 6671-6681, 1986.

Rex, M., Harris, N. R. P., von der Gathen, P., et al.: Prolonged stratospheric ozone loss in the 1995-96 Arctic winter, Nature, 389, 835-838, 1997.

Santee, M. L., Manney, G. L., Froidevaux, L., Read, W. G., and
Waters, J. W.: Six years of UARS Microwave Limb Sounder $\mathrm{HNO}_{3}$ observations: Seasonal, interhemispheric, and interannual variations in the lower stratosphere, J. Geophys. Res., 104, 82258246, 1999.

Santee, M. L., Manney, G. L., Livesey, N. J., and Waters, J. W.: UARS Microwave Limb Sounder observations of denitrification and ozone loss in the 2000 Arctic late winter, Geophys. Res. Lett., 27, 3213-2316, 2000.

Shine, K. P.: The middle atmosphere in the absence of dynamical heat fluxes, Q. J. R. Meteorol. Soc., 113, 603-633, 1987.

Sugita, T., Kondo, Y., Nakajima, H., et al.: Denitrification observed inside the Arctic vortex in February 1995, J. Geophys. Res., 103, 16221-16223, 1998.

Waibel, A. E., Peter, T., Carslaw, K. S., et al.: Artic ozone loss due to denitrification, Science, 283, 2064-2069, 1999. 